\title{
Lavandula stoechas L. Bitkisinin Uçucu Yağı Üzerinde Farmakognozik Araştırmalar*
}

\author{
Die Pharmakcgnostische Untersuchungen über das
} Aetherischen Öl von Lavandula stoechas L.

\author{
Nevin TANKER * *, Engin ŞARER * *, Vatandaş BAŞARAN * * *
}

Lavandula (Labiatae), Akdeniz memleketlerinde yayılış gösteren bir bitkidir. (1). Anadolu'da bu cinsin 2 türü yabanıl olarak yetişir: L. cariensis Boiss. ve L. stoechas L. (3). Bu türlerden birincisi üzerinde evvelce çalışılmıştır (7).

Çeşitli Lavandula türlerinden elde edilen uçucu yağlar, son yıllarda basılmış farmakopelerde (Ph. Helv. VI 1971, N.F. XVI 1975) bile kayıtlı olan ya da değişik amaçlarla kullanılan preparatlar içinde bulunan droglardir $(2,4,5,6)$.

Bu çalışmada gelişimi sırasında iklime karşı duyarlık göstermeyen ve memleketimizde kuru tepelerde, Marmara, Ege ve Akdeniz bölgelerinde yaygın olan Lavandula stoechas L. bitkisinin uçucu yağının hangi amaçla kullanılabileceği aydınlatılmağa çalışıldı.

\section{MATERYAL ve Y ÖNTEM}

İzmir çevresinden 1975 Nisan ve 1976 Mart aylarında toplanan Lavandula stoechas L. bitkisinin çiçekli dal uçlarından subuharı distilasyonu ile uçucu yağ elde edildi.

Susuz sodyum sülfat üzerinde kurutulan uçucu yağ, sarı renkli, keskin kokulu ve acı lezzetlidir.

Redaksiyona verildiği tarih: 21 Nisan 1977

* Mayıs 1976, "I. Bitkisel İlaç ilkel Maddeleri Toplantısı"nda teblĭ̆ edilmiştir.

** Farmakognozi ve Farmasötik Botanik Kürsüsü, Eczacılık Fakültesi, Ankara Üniversitesi.

*** Farmakognozi Kürsüsü, Eczacılık Fakültesi, Ege Üniversitesi. 
Uçucu yağın,

a) Volümetrik yöntemle miktarı

b) Fiziksel ve kimyasal özelikleri

c) Gaz kromatografi yöntemi ile bileşimindeki maddeler

d) Planimetre yöntemi ile bileşimindeki maddelerin miktarı saptand1.

Uçucu yağın gaz kromatografik analizi değişik koşullarda yapıldı:

I) Detektör : FID (Alev iyonizasyonu detektörü)

Kolon : $8 \mathrm{~m}$ uzunlukta, iç çapı $1.5 \mathrm{~mm}$ olan bakır spiral

Adsorban : Chromosorb W 60/80 mesh

Stasyoner faz : \% 10 Carbowax 1540

Sicaklık : $65^{\circ} \mathrm{C}$ izotermal (Det. $225^{\circ} \mathrm{C}$, Inj. $200^{\circ} \mathrm{C}$ )

Taşıyıcı gaz: Azot

Akış hızı : $30-35 \mathrm{ml} /$ dak.

II) Sicaklık : $125^{\circ} \mathrm{C}$ izotermal

Akış hızı : $25 \mathrm{ml} /$ dak.

(Diğer koşullar I deki gibidir.)

Elde edilen sonuçlar literatürdeki diğer lavanta türlerinden elde edilen uçucu yağlarla karşılaştırıldı.

Uçucu yağın bileşimindeki maddeler, analizi aynı koşullarda yapılan Lavandula cariensis uçucu yağındaki maddelerin bağıl tutuş zamanları ile karşılaştırılarak ve saf maddelerden yararlanarak saptand1 (7).

\section{B U L G U L A R}

Yapılan çalışmalar sonunda Lavandula stoechas L. bitkisinin uçucu yă̆ miktarı, çiçeklerde \% 0.86, yapraklarda ise \% 0.57 olarak bulundu.

Uçucu yağın fiziksel ve kimyasal özelikleri Tablo I de görülmektedir.

Uçucu yağın gaz kromatografi yöntemiyle yapılan analizi sonunda bileşiminde monoterpenik hidrokarbonlardan, $\alpha$ - pinen, kamfen, 
$\beta$ - pinen ve limonenin; oksijenli bileşiklerden, kâfur, fenkon, linalol, linalil asetat, sineol ve borneolün varlığı saptanmıştır. Bu maddelere ait bağıl tutuş zamanlan ve uçucu yağ içindeki \% miktarları Tablo II de verilmiştir.

Tablo I. L. stoechas uçucu yağının fiziksel ve kimyasal özelikleri

Yoğunluk, $20^{\circ} \mathrm{C}$

Kırılma indeksi

Asitlik indeksi

Sabunlaşma indeksi

Ester indeksi

Ester miktarı (\%)

$$
\begin{aligned}
& 0.9569 \\
& 1.4743 \\
& 5.96-6.12 \\
& 30.5 \\
& 24.4-24.6 \\
& 8.49-8.56
\end{aligned}
$$

\begin{tabular}{|c|c|c|c|}
\hline \multirow[t]{2}{*}{ Terpenler } & \multicolumn{2}{|c|}{ Bağıl tutuş zamanları } & $\%$ \\
\hline & Garbowax $1540,65^{\circ} \mathrm{C}$ & Carbowax $1540,125^{\circ} \mathrm{C}$ & \\
\hline$\alpha$-pinen & 4.8 & & 3.70 \\
\hline kamfen & 6.3 & & 3.32 \\
\hline$\beta$-pinen & 7.9 & & 1.11 \\
\hline limonen & 13.3 & & 2.44 \\
\hline sineol & & 3.3 & 4.07 \\
\hline fenkon & & 7.6 & 12.94 \\
\hline linalol & & 10.8 & 1.48 \\
\hline linalil asetat & & 11.8 & \\
\hline kâfur & & 13.0 & 23.29 \\
\hline borneol & & 19.8 & 6.87 \\
\hline
\end{tabular}

Tablo I I. L. stoechas uçucu yağında bulunan maddelerin bağıl tutuş zamanları ve \% miktarları

TART I ŞMA ve SONUÇ

Lavandula stoechas uçucu yağının fiziksel ve kimyasal özelikleri literatürdeki diğer lavanta türlerinden elde edilen uçucu yağlarla karşılaştırmalı olarak Tablo III de belirtilmiştir.

Tablodaki değerlerden anlaşılacağı gibi Lavandula stoechas L. bitkisinden elde edilen uçucu yağ, Aspik esans ve Lavandula cariensis uçucu yağı ile benzerlik göstermektedir.

$\mathrm{Bu}$ uçucu yağın gaz kromatogramından yararlanarak planimetre ile ölçülen miktarları da Tablo IV de, diğer uçucu yağlarla karşılaştırılmıştır. 
Tablo III. L. stoechas uçucu yağının diğerleri ile, fiziksel ve kimyasal özelikleri yönünden karşılaştırılması

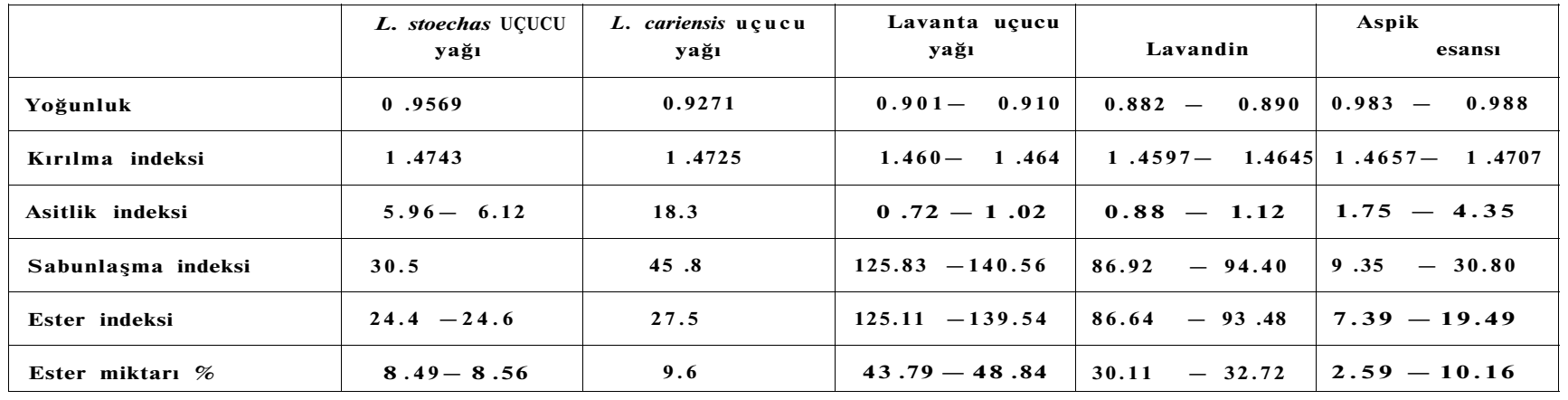


Tablo IV. L. stoechas uçucu yağının diğerleri ile, kimyasal bileşim yönünden karşılaştırılması

\begin{tabular}{|l|c|c|c|c|c|}
\hline & $\begin{array}{c}\text { L. stoechas } \\
\text { uçucu yağı } \\
\%\end{array}$ & $\begin{array}{c}\text { L. cariensis } \\
\text { uçucu yağı } \\
\%\end{array}$ & $\begin{array}{c}\text { Lavanta } \\
\text { uçucu yağı } \\
\%\end{array}$ & $\begin{array}{c}\text { Lavandin } \\
\%\end{array}$ & $\begin{array}{c}\text { Aspik } \\
\text { esansı } \\
\%\end{array}$ \\
\hline Kâfur & 23.29 & 30 & 0.2 & 7 & 14 \\
\hline Fenkon & 10.87 & 18 & - & - & - \\
\hline Sineol & 4.07 & 5.3 & 1 & 7.6 & $36-47$ \\
\hline $\begin{array}{l}\text { Linaloi ve } \\
\text { linalil ase- } \\
\text { tat }\end{array}$ & 1.5 & 2 & $50-60$ & $50-60$ & $30-40$ \\
\hline
\end{tabular}

Bu sonuçlara göre Lavandula stoechas uçucu yağı az miktarda linalol ve linalil asetat, önemli miktarda kâfur (\% 23.29) ve fenkon (\% 10.87) taşıması yönünden $L$ - cariensis uçucu yağı ile benzerlik göstermektedir.

L. stoechas uçucu yağının taşıdı̆̆ kâfur, fenkon ve sineolden dolayı eczacılıkta kullanılma olană̆ı vardır.

\section{Ö Z E T}

Bu çalışmada Lavandula stoechas L. bitkisinden elde edilen uçucu yağın fiziksel ve kimyasal özelikleri ile bileşimindeki maddeler saptand1.

Elde edilen sonuçlara göre Lavandula stoechas bitkisinin uçucu yă̆ verimi, çiçeklerde \% 0.86 , yapraklarda \% $0.57 \mathrm{dir}$.

Gaz kromatografi yöntemiyle yapılan analiz sonucunda uçucu yağda monoterpenik hidrokarbonlardan, $\alpha$ - pinen, kamfen, $\beta$ - pinen ve limonen, oksijenli bileşiklerden kâfur, fenkon, sineol, borneol, linalol ve linalil asetat bulundu.

Uçucu yağın kromatogramında yapılan planimetrik ölçüm sonuçlarına göre, bileşiminde \% 23.29 kâfur, \% 10.87 fenkon, \%4.07 sineol, \% 1.5 linalol ve linalil asetat olduğu saptand.

\section{Z U S A M M E N F S S U N G}

In diesem Arbeit wurden durch Dampfdestillation aus den Blüten $(0.86 \%)$ und Blaettern $(0.57 \%)$ von Lavandula stoechas L. ein 
aetherisches Öl gewonnen. Die physikalische Eigenschaften und chemische Zusammensetzung wurden von diesem Öl untersucht.

Mit Hilfe der Gaschromatographie wurden im Öl als Terpenkohlenwasserstoffe; $\alpha$ - Pinen, Camphen, $\beta$ - Pinen und Limonen, als sauerstoffhaltige Stoffe; Gampher, Fenchon, Cineol, Borneol, Linalol und Linalylacetat identifiziert.

Die quantitative Bestimmung des Öls wurden mit der Methode "Planimetrie" gemacht.

Das aetherischen Ö1 von Lavandula stoechas im Gegensatz zum Lavenderöl, Lavandinöl und Spiköl nur in sehr geringen Mengen von Linalol und Linaly lacetat enthaelt. Aber das Gehalt von Campher (23.29 \%) und Fenchon (10.87\%) ist ziemlich hoch.

\section{L İ T E R A T Ü R}

1. Gildemeister, E., Hoffmann, Fr., Die Aetherischen Öle, Band VII, 4. Auflage, Akademie Verlag, Berlin (1961).

2. Leclerc, H., Precis de Phytotherapie, Masson et $\mathbf{C}^{\mathrm{ie}}$ Editeurs, Paris (1966).

3. Öztı̆̆, F., Ren. Fac. Sc, Univ., Istanbul 10/B, 251 (1945).

4. Perrot, E., Paris, R., Les Plantes Medicinales 2, Presses Üniversitaires de France, Vendome (1971).

5. Pouches W. A., Perfumes, Cosmetics and Soap, Vol. 1, $8^{\text {th }}$ ed. Chapuran and Hall, London (1974).

6. Ibid. Vol. 2 (1974).

7. Tanker, N., Şarer, E., J. Fac. Pharm. Ankara, 5, 19 (1975). 